\title{
Potencial artístico e educacional da memória subversiva da cidade
}

\section{Mariana Lydia Bertoche}

Pesquisadora mestranda em Processos Artísticos Contemporâneos no Programa de Pós Graduação em Artes da Universidade do Estado do Rio de Janeiro (PPGARTES - UERJ), Professora Substituta de Artes Visuais do Colégio de Aplicação da Universidade Federal do Rio de Janeiro (CAp-UFRJ) e Artista Visual.

Contato: blydiamar@gmail.com

\section{RESUMO}

O presente artigo traça relaçóes entre três objetos de análise: alguns trabalhos da série fotográfica Buena Memória do argentino Marcelo Brodsky, o Memorial da Resistência de São Paulo e o Ocupa DOPS no Rio de Janeiro; evidenciando a importância de se haver espaços institucionais que promovam exposiçóes com produçóes artísticas voltadas para a memória na capital fluminense. O texto analisa a fotografia "La Clase" e sua "Puente de la Memória" com a cidade de Buenos Aires, relacionando suas reflexóes com o histórico e o potencial desses dois lugares de memória no Brasil como possíveis espaços de uma narrativa arte-educacional náo hegemônica e libertadora.

Palavras-chave: Memória; Ditadura; Arte-educação; Lugares de memória.

\section{ABSTRACT}

The present article traces relations between three objects of analysis: some works from the photographic series "Buena Memória" by the Argentinian Marcelo Brodsky, the Memorial da Resistencia de São Paulo and the Ocupa DOPS movement in Rio de Janeiro; evidencing the importance of having institutional spaces which promote exhibitions with artistic productions about memory in the Fluminense capital. The text analyses the photograph "La Clase" and its "Puente de La Memória" with the city of Buenos Aires, relating its reflections with the history and potential of these two places of memory in Brazil as possible spaces of an art educational non hegemonic and freeing narrative.

Key-Words: Memory; Dictatorship; Art education; Places of memory. 


\section{MEMÓRIAS ENEVOADAS DE ESQUECIMENTO}

Estamos próximos de completar 40 anos de 28 de agosto de 1979, data em que foi promulgada a Lei da Anistia no Brasil. Desde então, o que se construiu de política de memória de não repetição no nosso país? Essa lei, que concedia perdáo tanto aos militantes e guerrilheiros condenados pelo regime militar, quanto a militares envolvidos em práticas de violação de Direitos Humanos com o aval do Estado, foi importante na época (apesar de já ter sido questionada pela Comissão Interamericana de Direitos Humanos mais de uma vez, assim como recomendada a sua reinterpretação). Ainda assim, nesse mesmo 1979 e por mais longos anos, vivia-se em pleno regime ditatorial no Brasil. A censura, as prisóes, os desaparecimentos, as torturas e o medo generalizado faziam parte do cotidiano da população resistente no país, que bradava pelo fim do autoritarismo e a volta da democracia nas terras tupiniquins. De certa forma, virou-se (forçosamente) uma página da história do Brasil.

Alguns dias antes dessa promulgação, em nossa vizinha Argentina, Marcelo Brodsky ${ }^{1}$ teve sua vida diretamente afetada pelas ditaduras latino-americanas. Em 14 de agosto de 1979, seu irmão Fernando Rúbens Brodsky foi sequestrado pelas forças do Regime, permanecendo desaparecido até hoje. Em exílio em Barcelona até meados da década de 90, o artista tornou-se fotógrafo, e ao retornar para sua cidade natal recuperou uma fotografia antiga de sua turma do Colégio Nacional de Buenos Aires de 1967, além de outras fotografias de sua família da mesma década. Ao se deparar com esse material, o fotógrafo começou a desenvolver um trabalho poético aliado a um ativismo político que tem como principal motor a memória e a imagem. O tra- balho de Marcelo surge com a potência de revelar essas imagens e tirar a névoa de toda uma memória coletiva, já que "toda imagem do passado (...) corre o risco de desaparecer com cada instante presente que nela não se reconheceu" (BENJAMIN, 2012, p. 161). No trabalho artístico de Marcelo o que acontece é justamente o reconhecimento mútuo dessas imagens, com um diálogo entre passado e presente constante (que será melhor explicitado mais adiante).

No Brasil, apenas em 2012 foram criadas as Comissões da Verdade, com adiamento que posiciona o país como um dos países mais atrasados entre os que presenciaram ditaduras na América Latina (NEPOMUCENO, 2015, p. 12). Isso certamente carrega até hoje consequências perversas à sociedade como um todo, $\mathrm{e}$ em especial aos sobreviventes e familiares, numa conjuntura em que há um crescente desmantelamento da Comissão da Anistia (com 6 membros militares e 1 abertamente contra a Comissão da Verdade e a reparação a perseguidos políticos) e a tentativa de se instaurar uma CPI (Comissão Parlamentar de Inquérito) justamente sobre essas poucas tentativas de reparação material de violaçóes do Estado. Isso, sem contar, com um aberto ataque midiático que intitula como "farra das indenizaçôes" a conquista de direitos humanos ainda não suficientes para que se tenha uma reparação de fato aos crimes de lesa humanidade. Impossível não citar fundamentalmente, dentro dessa conjuntura (em que se vê a estagnação de trabalhos por justiça e reparação e o avanço do revisionismo sobre os crimes militares), a chegada à presidência ${ }^{2}$ da República de Jair Bolsonaro, figura que abertamente homenageia torturadores e relativiza os crimes da ditadura sempre 
que pode, tendo inclusive autorizado as comemoraçôes à data do golpe de 1964 nos quartéis, além de ter sido condenado pela justiça por suas declaraçóes de ódio a pessoas negras e LGBTQI.

Vive-se num contexto de acirramento dessa violência, dentro da democracia, com as mesmas práticas intensificadas na ditadura empresarial-militar. ${ }^{3}$ Durante os períodos de ditadura (com Vargas e, depois, os militares) para além da perseguição a guerrilheiros, pessoas de esquerda e contrárias ao governo, a coerção social exercida sobre a população pobre, negra e de periferia, que desde a diáspora africana sofre torturas, desaparecimentos e sérias violaçôes de direitos humanos, também se intensificou. ${ }^{4}$ As ditaduras tornam a tortura regular, mas isso não quer dizer que são sua exclusividade. Para determinados corpos, certas violaçóes fazem parte de um tempo de injustiça que ainda não cessou. Esse "virar a página" prevaleceu, pela conveniência mútua de antigos e novos governantes em evitar conflitos e garantir estabilidade (GÓMES, 2014, p. 72).

Desmemoriado, nosso país carece de mais iniciativas da Justiça de Transição. Defendidas pela ONU, elas são: "o conjunto de abordagens e mecanismos (judiciais e extra-judiciais) e estratégias adotado por cada país para enfrentar o legado de violência em massa do passado, para atribuir responsabilidades, para exigir a efetividade do direito à memória e à verdade e para fortalecer as instituiçôes com valores democráticos" (SOARES, 2014, p. 103). Uma dessas aproximaçôes poderia ser a criação de espaços de memória.

Como a memorialização é quase sempre contestada (enquanto processo), quando cuidadosamente abordada e conduzida, pode servir para promover o debate e engajamento público construtivo. Além disso, com recursos limitados, locais de memória podem ser ativados através de programas de educação para garantir o diálogo e o engajamento público existente. (NAIDU, 2010, p.16)

Programas de educação e cultura que resgatem pontos de vista não hegemônicos - pois sem a memória dos vencidos não é possível entender o passado, nem as heranças advindas dessa época (GÓMES, 2014, p. 74). É apenas a partir de uma perspectiva de concepção não determinista da História que se educa para a democracia, para a liberdade, para a responsabilidade ética (FREIRE, 2000, p. 126) - e é disso que nossa Justiça de Transição carece. De espaços memoriais que garantam a diversidade de protagonismos, que dêem visibilidade a memórias e objetos de cultura que por algum motivo estão silenciados ou não visibilizados. Espaços educativos que promovam visitas que dêem importância ao pensamento crítico, já que "quanto mais crítico um grupo humano, tanto mais democrático e permeável, em regra. Tanto mais democrático, quanto mais ligado às condições de sua circunstância" (Ibdi, 1981, p.95).

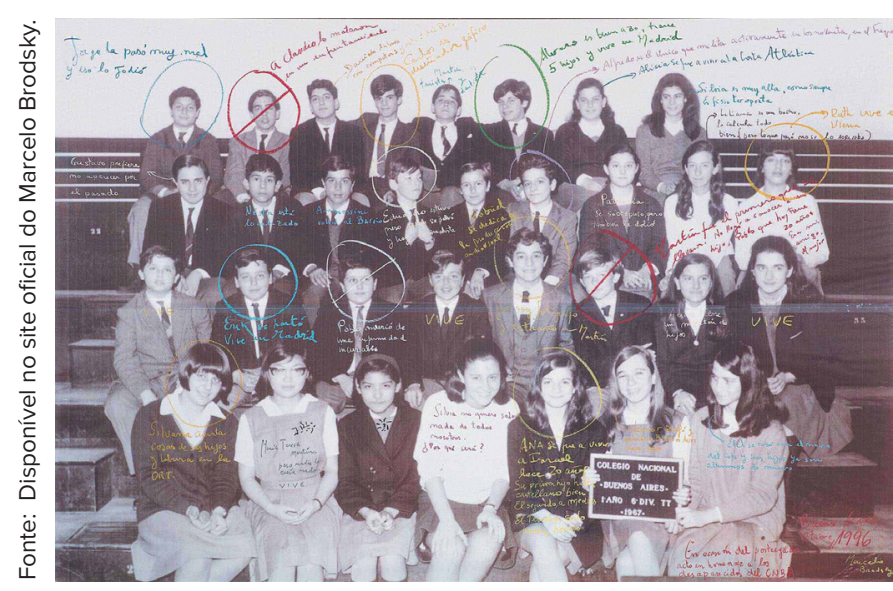

Figura 1. Fotografia de 1967 com intervenção artística e memorialística de Marcelo Brodsky realizada em 1996. 
Como diria Leonardo Boff (1938-), "a memória é subversiva, e uma das coisas que ocorreram em nosso país com mais peso foi o ato de apagar a memória dos vencidos" (NEPOMUCENO, 2015, p.54). ${ }^{5}$ Mas apesar da dificuldade em lidar com a memória do passado, há algumas iniciativas que se rebelam contra a supressáo dessa história. Projetos que tentam tirar a pedra de cima das páginas viradas e mostrá-las à população, para que nunca mais se repitam.

\section{BUENA MEMORIA}

Um desses projetos é a série com 70 fotografias e 2 vídeos (que gerou um livro que foi reeditado em outros idiomas e catálogos) Buena Memoria, do artista visual e ativista político Marcelo Brodsky, de Buenos Aires - em especial a fotografia com intervenção textual do artista "La Clase" (Figura 1). Após desaparecimento de seu irmão e exílio, Marcelo viu a necessidade de recuperar o contato com os antigos colegas daquela foto de turma de 1967 e saber suas histórias, e começou a montar a princípio uma reportagem (que depois se revelou como série fotográfica). A proposta do artista era que cada um de seus companheiros fosse fotografado, com elementos de sua vida atual, ao lado da antiga foto de escola. Três desses colegas da fotografia haviam morrido - sendo dois deles, Cláudio e Martín, seqüestrados pela ditadura militar. A partir do reencontro e das histórias de seus colegas de classe, o artista desenvolveu uma forma visual de falar sobre essas perdas, fazendo uma intervenção gráfica e textual nessa mesma foto da década de 60 (Figura 1).

O rosto dos colegas que já não estão conosco estão riscados, sendo de vermelho as relativas aos dois desaparecidos. "Mataram Claudio em um confronto", está ao lado de um deles. "Martín foi o primeiro que levaram. Não chegou a conhecer seu filho Pablo, que hoje tem 30 anos. Era meu amigo, o melhor", revela Marcelo em inscriçôes sob a imagem do uniforme branco do Colégio. Nos outros colegas, informaçôes sobre o que fazem hoje, construindo um elo com o passado, como "Silvia é muito alta, como sempre. É fisioterapeuta", "Eduardo esteve preso, mas se salvou", "Ruth vive com sua esposa em Helsinke", ou simplesmente "VIVE" - como um lembrete sobre a importância da sobrevivência de nossos jovens. Abaixo, próximo ao local e data da intervenção artística (Buenos Aires, 1996), há também a inscrição "em homenagem ao postergado ato em homenagem aos desaparecidos da CNBA".

A frase se refere a uma ação promovida pelas Madres de Plaza de Mayo Línea Fundadora, a Fundación Memoria Histórica y Social Argentina, o Centro de Estudiantes del Colegio Nacional de Buenos Aires e o próprio Marcelo, em que finalmente se reconhece e se faz uma homenagem aos 98 desaparecidos $^{6}$ no saguão principal do Colégio, em outubro de 1996. Na ocasião, houve uma exposição dessas fotos contemporâneas feitas pelo fotógrafo, além da fotografia de 1967 ampliada com a intervenção visual do artista. Essa fotografia, já com reproduçôes na coleção da Pinacoteca do Estado de Sáo Paulo, do Metropolitan Museum em Nova York, da Tate, em Londres e do Museo Nacional de Bellas Artes, em Buenos Aires, encontra-se também atualmente permanentemente no pátio central da escola, o Colegio Nacional de Buenos Aires, onde há uma placa com os nomes dos alunos desaparecidos e atualmente acontecem os eventos, debates e assembléias de estudantes.

A partir da exposição dessa foto justamente em seu local de origem, reatualizando as informaçôes contidas naquela imagem a partir de novas inscrições e palavras, Marcelo reconstrói o que ele mesmo chama 
de Ponte da Memória (que, dentro do livro, da exposição e da série Buena Memoria continua a investigação imagética da memória, agora a partir de fotografias de alunos atuais do Colegio frente - e refletidos sobre os estudantes da década de 60 e suas histórias pessoais e coletivas) (Figura 2). $\mathrm{O}$ artista continua a série investigando as imagens da década de 1960 recuperadas e reinscreve-as, agora no campo da arte e da cultura, possibilitando uma narrativa visual, poética, histórica e política de si mesmo e de um período.

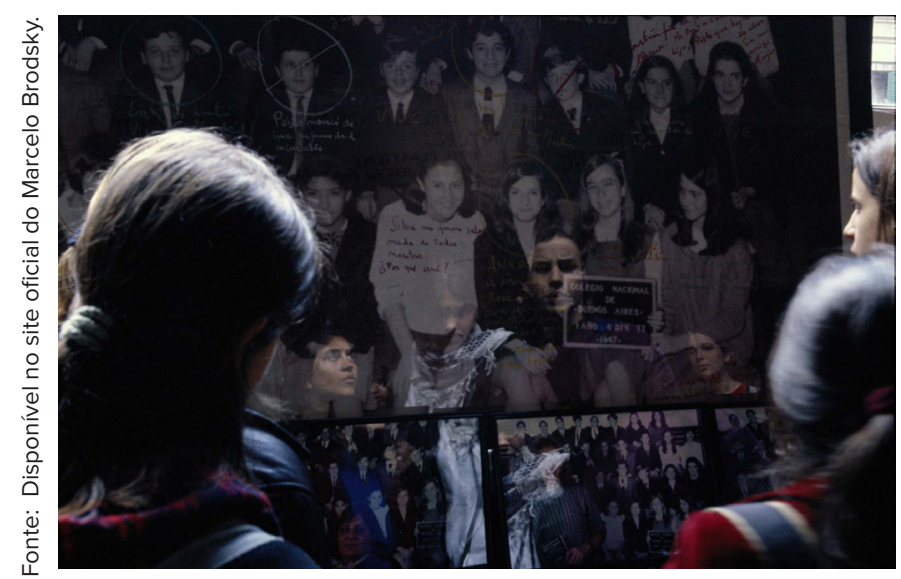

Figura 2. Fotografia de Marcelo Brodsky em exposição da série Buena Memoria no Colegio Nacional de Buenos Aires, em 1996. Disponivel no site oficial do artista.

Ao falar desses dois desaparecidos de sua turma, Marcelo está falando de todos os desaparecidos dessa escola, e também de sua cidade, Buenos Aires, assim como de outros seqüestrados pela violência Estatal na América Latina. Não à toa, a primeira cidade a receber a exposição Buena Memoria fora da Argentina, em 1998, em seu Museu da República, foi justamente o Rio de Janeiro - cidade que foi e continua sendo palco de importantes episódios políticos, uma vez que foi por muito tempo capital do país (enquanto Estado da Guanabara), e de violaçóes constantes aos Direitos Humanos. A exposição aconteceu graças a uma parceria do Museu com o Instituto do Patrimônio His- tórico e Artístico Nacional (IPHAN) e o Ministério da Cultura da época e pode ser interpretada como uma evidência da demanda da população fluminense por esse tipo de trabalho e exposição (de processos artísticos e objetos da cultura que dialoguem com a memória de uma época que pode estar esquecida). Não é possível ignorar que logo após sair do Rio de Janeiro o trabalho seguiu para a Bienal de Vigo, na Espanha, e depois para uma exposição em uma galeria em Nova York, e a cidade fluminense foi pioneira no seu reconhecimento internacional. ${ }^{7}$ No ano seguinte, o trabalho voltou para o Brasil, desta vez em São Paulo, no Museu da Imagem e do Som. Ambas as cidades tem projetos que são fundamentais para se pensar e germinar - a construção de políticas educacionais e culturais de memória, reparação e não-repetição das violaçôes de Direitos Humanos no Brasil. Um deles abrigou novamente a exposição da série em São Paulo, em 2010, dessa vez dentro de um lugar que é também um documento histórico importante sobre a memória resistente de dois períodos de ditadura no Brasil.

\section{MEMORIAL DA RESISTÊNCIA DE SÃO PAULO}

Localizado nos arredores da Estação da Luz, o antigo prédio do Departamento Estadual de Ordem Política e Social de Sáo Paulo (DEOPS/SP) hoje abriga o Memorial da Resistência de São Paulo, em experiência pioneira no Brasil. O edifício foi projetado no início do século como escritório e armazém central da Estrada de Ferro Sorocabana, de 1914 a 1940. Só a partir desse ano, abrigou o DEOPS/SP, vinculado ao controle do cidadão brasileiro, tanto durante o Estado Novo e a ditadura empresarial-militar quanto em tempos de democracia. Essa instituição, durante 69 anos, usou de práticas repressivas violentas, como a tortura, o cárcere e a execução - e o prédio, como documento histórico 
dessas violaçóes de direitos humanos, carrega consigo essa memória. E como um local historicamente ligado à repressão e à barbárie hoje abriga um Memorial da Resistência?

Em 1983, com a extinção do DEOPS e início da democratização do país, o edifício passou a sediar a Delegacia de Defesa do Consumidor (Decon), até 1997. A partir de uma forte atuação da sociedad civil, de organizaçóes de Direitos Humanos e instâncias governamentais junto ao Poder Público, a administração do prédio foi transferida da Secretaria de Justiça para a Secretaria de Estado da Cultura, em 1998 (ARAÚJO; BRUNO, 2009, p. 29). Em 1999, o prédio foi tombado pelo Conselho de Defesa do Patrimônio Histórico, Artístico, Arqueológico e Turístico do Estado de São Paulo (Condephaat) e começaram as obras de restauração. No mesmo ano, o potencial cultural do prédio já começa a se mostrar, a partir de dois eventos acontecidos no edifício. Um foi a exposição temporária "Anistia 20 anos", em rememoração à promulgação da Lei da Anistia, em 1979. Outro foi a apresentação Teatral "Lembrar é Resistir", concebida por Analy Alvarez (1942-) e realizada também nas dependências do Departamento de Ordem Política e Social do Rio de Janeiro (DOPS/RJ), em 2001. Ambas as atividades marcaram "a nova fase do uso do edifício, como um espaço livre e democrático, sem permitir que fossem esquecidas as histórias de resistência e de opressão impregnadas nas paredes desse lugar" (ARAÚJO; BRUNO, 2009, p. 31).

Já em 2002, o prédio foi inaugurado como Memorial da Liberdade, sob responsabilidade do Arquivo Público do Estado até 2006, quando passou a ser da Pinacoteca do estado (que já ocupava boa parte do Edifício com a Estação Pinacoteca). Além de ter sido descaracterizado pela reforma, o antigo Memorial não agradava os militantes políticos e o Fórum Permanente de Ex-Presos e Perseguidos Políticos do Estado de São Paulo, já que não dava espaço às experiências pessoais dos que passaram por aquele lugar, além do nome um tanto quanto contraditório - como chamar de Memorial da Liberdade um lugar que suprimiu a liberdade de tantos presos políticos? Foi a partir desse descontentamento que começou a se formar o que permanece até hoje.

O Fórum, criado quando o Governo do Estado abriu processo de reparaçáo para dar suporte a quem ainda precisava da Anistia, solicitou ao poder público entre 2006 e 2007 a utilização desse prédio enquanto Memorial da Resistência. A partir daí, inaugurou-se a primeira exposiçáo - como marco do novo espaço expográfico, em 2008 - e começou o processo de elaboração do projeto. Ele foi feito a partir da "parceria e cumplicidade de alguns dos protagonistas das experiências vivenciadas nesse espaço carcerário" (ARAÚJO; BRUNO, 2009, p. 54), contribuindo para a reconstituição das celas e recuperação da memória do conjunto prisional até 2009 - com sua inauguraçáo definitiva. Hoje, dez anos depois, como será que se encontra nesse edifício?

O Memorial da Resistência de São Paulo hoje conta com cinco principais abordagens: as Exposiçôes Temporárias e Permanente, que tem como pilar fundador a memória da resistência; a Pesquisa, com uma equipe especializada e parcerias com universidades coletando testemunhos e desenvolvendo o Programa Lugares de Memória, que realiza coletas de testemunho e exposiçôes itinerantes em outras cidades de São Paulo; o Centro de Referência, com arquivos da ditadura fixos no Memorial e em seu site; a Ação Cultural, com diversas atividades, entre elas palestras, lançamento de livros, apresentação de filmes, peças de teatro, etc.; e 
a Ação Educativa, que além de desenvolver as visitas, faz encontros com educadores, distribuindo material educativo desenvolvido por sua equipe, encontros de aprofundamento, contaçôes de histórias para o público infantil e rodas de conversa com ex-presos políticos - que continuam o contato e o trabalho em conjunto com o Memorial, já que "sem a memória e a luta dos que não querem esquecer, não há verdade nem realidade, como também não se mantém a atualidade da injustiça nem a possibilidade de fazer justiça" (GÓMES, 2014, p. 75).

Essa instituição tem um trabalho que potencializa a recuperação de certas memórias invizibilizadas da sociedade paulistana. Seu público principal são alunos do Ensino Médio e Superior, além de um número menor de Ensino Fundamental, grupos de terceira idade e expressiva quantidade de público espontâneo. Como defende Paulo Freire (1921-1997) em Pedagogia da Indignação,

toda prática educativa libertadora, valorizando o exercício da vontade, da decisão, da resistência da escolha; o papel das emoçóes, dos sentimentos, dos desejos, dos limites; a importância da consciência na história, o sentido ético da presença humana no mundo, a compreensão da história como possibilidade jamais como determinação, é substantivamente esperançosa e, por isso mesmo, provocadora de esperança (FREIRE, 2000, p.48)

Esperança que se estende para a criação de novos espaços como este, espalhados por todo território brasileiro, e fortalecimento das iniciativas nos lugares de memória já existentes. Apesar de ser um dos poucos projetos sobre memória desse tamanho e estrutura no
Brasil, no início deste ano foi fundada a Rede Brasileira de Lugares de Memória (REBRALUME), que, ao estilo de redes existentes na Argentina, Chile e Colômbia, permitirá um ambiente coletivo de intercâmbio e trocas entre grupos e instituiçôes que visam a promoção de memória das violaçôes dos direitos humanos do país. Participam dessa rede, além do Memorial da Resistência de São Paulo, diversas instituiçóes, entre elas o Ocupa DOPS no Rio de Janeiro.

\section{CAMPANHA OCUPA DOPS NA TRANSFORMAÇÃO DO EX-DOPS EM ESPAÇO DE MEMÓRIA E RESISTÊNCIA.}

Inaugurado em 5 de novembro de 1910 na esquina da Rua da Relação com a Rua dos Inválidos, o prédio foi projetado para sediar a repartição Central de Polícia. $\mathrm{O}$ edifício sempre esteve vinculado à coerção de reaçôes políticas que pudessem de alguma forma comprometer a "ordem pública". Logo no início, reprimia negros e pobres, proibia manifestaçóes religiosas de origem africana e a capoeira, numa época em que ainda se prendia por "vadiagem". Durante o Estado Novo, funcionou como Delegacia Especial de Segurança Política e Social (DESPD), de 1933 a 1944, e na Ditadura Militar funcionou como Departamento de Ordem Política e Social do Estado da Guanabara (DOPS/GB), de 1962 a 1975, quando passou a se chamar Departamento Geral de Investigações Especiais (DGIE), até 1983.

Em 7 de maio de 1987, foi tombado pelo Instituto Estadual do Patrimônio Cultural (INEPAC) e em 2010 começou um processo de restauração externa. De "eclético", além do estilo arquitetônico, o prédio não tem nada, já que, independente da época em que se inseria, a edificaçáo sempre esteve relacionada a políticas de inibição de movimentos e ideais considera- 
dos "subversivos", participando de todos os capítulos da História de repressão da sociedade carioca.

Apesar das semelhanças com o prédio do Memorial da Resistência de São Paulo, o edifício ainda hoje está sob posse da Secretaria de Estado de Segurança do Rio de Janeiro, mais especificamente à Polícia Civil e, apesar do movimento intenso de ex-presos políticos e militantes no Rio de Janeiro, a transformação do prédio, que já foi prometida inclusive por um governador do estado $^{8}$, tem sofrido pelo embarreiramento na cessão do prédio.

Formada desde 2013 por diversas organizaçôes, coletivos, militantes autônomos e ex-presos políticos, a Campanha Ocupa-DOPS tem o objetivo de transformar o prédio do ex-DOPS em uma referência em Espaços de Memória e Resistência. ${ }^{9}$ Sua proposta é utilizar o prédio com: exposição permanente sobre a repressão e resistência política e exposições temporárias; eventos culturais e educacionais (debates, seminários temáticos, testemunhos, festivais de cinema, cursos, etc.); um espaço para estudos e biblioteca especializada nos temas sobre Memória, Verdade e Justiça; disponibilidade de acervos da repressão no RJ e do material das Comissóes da Verdade para consulta pública e digitalizada; espaço de trabalho para reunióes e atividades de movimentos e organizaçóes da sociedade civil; um núcleo de estudo, pesquisa e atuação política no campo da Memória, Verdade e Justiça, estabelecendo a relação entre as violaçóes do passado com as do presente; além de uma área de apoio às políticas públicas de defesa e promoção dos direitos humanos que existem formalmente no estado do Rio de Janeiro.

A campanha realiza diversas atividades em frente ao prédio desde a sua criação, transformando o local, durante esses eventos, em um espaço de efervecência política e cultural. As açôes contam com palestras, debates, exibição de filmes, rodas de capoeira, música, peças de teatro, performances, lançamento de livros, exposiçóes, entre diversas outras coisas, com o objetivo de chamar atenção da sociedade e dos representantes de Estado para a questão do prédio e sua imediata transformação em Centro de Memória.
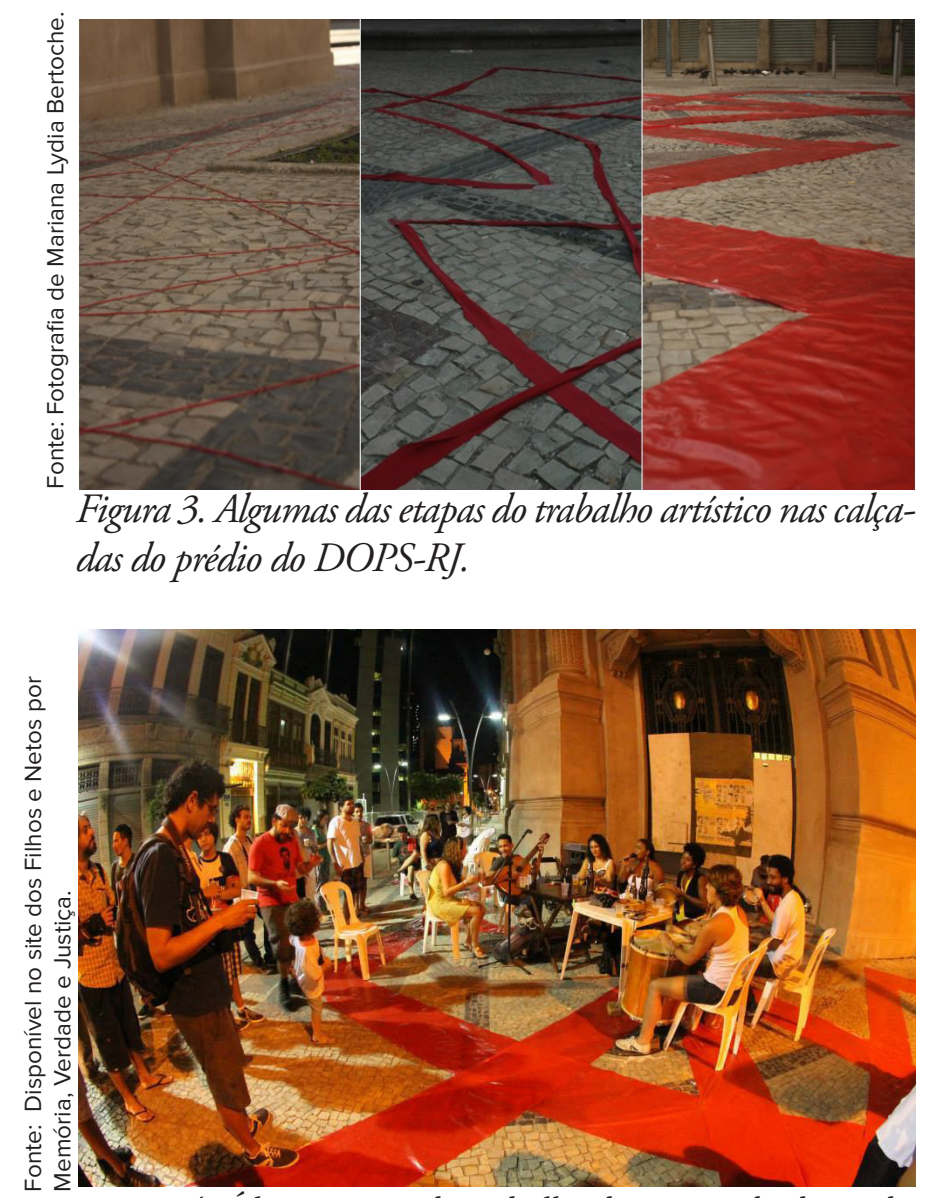

Figura 4. Última etapa do trabalho durante roda de samba do Comuna Que Pariu, no dia 4 de abril de 2015.

Uma dessas açôes artísticas foi a última etapa da instalação seriada Rota Transbordada, realizada no ato em descomemoração aos 51 anos do golpe militar de 1964, pela artista visual Mariana Lydia Bertoche, em 4 de abril de 2015. O trabalho aconteceu nas calçadas da esquina do DOPS no início do ano, em quatro 
etapas. Familiar de ex-preso político, a artista constrói uma cartografia afetiva vermelha no entorno do prédio - ela registra, a partir de linhas que formam um emaranhado cartográfico, o transbordamento de uma memória de silenciamento e ausências violentas. A cada uma das etapas (Figura 3), após a montagem, o trabalho era suprimido e retirado horas depois. A primeira montagem da instalaçáo foi em 10 de janeiro, com linhas finas. A segunda instalação foi em 23 de fevereiro, com outras linhas, mais grossas. A terceira, em 8 de março, já contava com fitas grossas de malha. A última, do dia do ato, já transbordava a linha vermelha a uma densa ocupação da calçada, com uma lona que foi palco de açóes durante todo o dia, com homenagens, apresentaçôes performáticas, falas políticas e roda de samba (Figura 4). O trabalho só terminou quando foi retirado pela última vez, não sabe-se por quem ou quando, da rua. $\mathrm{O}$ que sobrou do trabalho foram as fotos e registros em texto sobre a ação realizada numa dessas açóes culturais do movimento.

Infelizmente, atualmente o prédio encontra-se de portas fechadas, inacessível à população, e tem uma placa que indica que ali é o "Museu da Polícia Civil". Enquanto isso, o Ocupa DOPS já possibilitou, a partir uma articulação que envolveu também a Comissão de Anistia do Ministério da Justiça e a Secretaria Estadual de Cultura, a elaboração de um plano museológico que contempla as necessidades levantadas tanto pela Comissão da Verdade, quanto de familiares, ex-presos, membros da sociedade civil e especialistas no assunto. Só lhes falta o essencial - o prédio, a verba para implementação e o apoio efetivo do Governo do Estado para sua realização.

Além do prédio representar a barbárie e a violação de direitos humanos, seu gerenciamento pode esconder grave descaso com os arquivos da ditadura. Diferente do DEOPS/SP, que passou seus documentos para o Arquivo Nacional ainda na década de 90, no DOPS/ $\mathrm{RJ}$ essa transferência não foi feita, e eles se encontram no prédio, podendo estar sujeitos às traças, às aranhas, à umidade e a possíveis desaparecimentos. Em 2014 foram feitas duas diligências da Comissão Estadual da Verdade (CEV-RJ), onde foi comprovado que havia documentos importantíssimos ligados ao período militar, e que puderam constatar que pode ter sumido número considerável de documentos. Isso demonstra ainda mais que o prédio não deve ficar nas mãos da Polícia Civil do Rio de Janeiro, que pode estar tratando com descaso a questão da memória dos resistentes do período militar.

Como uma ação de importância significativa para a memória dos cidadãos fluminenses, a transformação do prédio do ex-DOPS/RJ segue sua trilha, com dificuldades e pequenos passos, na esperança de que em breve será possível entrar naquele prédio para ouvir a história dos resistentes e ver trabalhos de arte que dialoguem com essa memória e narrativa contra-hegemônica. "É a partir deste saber fundamental: mudar é difícil mas é possível, que vamos programar nossa ação político-pedagógica" (FREIRE, 1996, p.88).

\section{MEMÓRIA, ARTE E EDUCAÇÃO NA CONSTRUÇÃO DE UMA CULTURA DE DIREITOS HUMANOS}

Entre as brumas do esquecimento, as cenas de violaçôes aos direitos humanos encontram-se perdidas e assumem espaço reincidente na contemporaneidade. A arte, como lugar de exercício investigativo da liberdade, pode ser um dos meios potentes para se trabalhar as subjetividades e se promover a memória ativa de uma cidade resistente que relaciona passado e presente o tempo todo. Entendendo que "o conceito de 
memória, produzido no presente, é uma maneira de pensar o passado em função do futuro de que almeja” (GONDAR, 2005, p.16), e que um dos papéis da arte pode ser "gerar uma demanda cuja satisfação plena ainda teria de aguardar tempos futuros" (BENJAMIN, 2012 , p. 30), trabalhos artísticos que dialogam com as memórias dessas cidades podem ser campo fértil para a construção de uma cultura dos direitos humanos. Documentos, prédios, fotografias, depoimentos, objetos de arte, rastros, lidos como testemunho (seja dentro ou fora do campo da arte), tem a capacidade de, no presente, sob novos olhares e debruçamentos, ultrapassar os limites do individual e particular para encostar e dialogar com questóes mais amplas. Sem deixar de considerar que do ponto de vista da vítima não há equiparação entre as catástrofes (SELIGMANN-SILVA, 2008, p.74), "nele [o testemunho], de um modo característico para a nossa pós-modernidade, o universal reside no mais fragmentário" (SELIGMANN-SILVA, 2003, p.80).

Dessa maneira, ter instituiçóes como o Memorial da Resistência de São Paulo em várias cidades do Brasil (como no prédio do DOPS/GB no Rio de Janeiro) - que recebam trabalhos artísticos como Buena Memoria e tantos outros que dialogam sensivelmente a memória social e o esquecimento como conceitos éticos e políticos (GONDAR, 2005, p.16) (HUYSSEN, 2014, p. 157); que incentivem a pesquisa e produção de conhecimento sobre direitos humanos e que possibilitem (como espaços de educação que são) uma narrativa educacional não hegemônica e libertadora -, assim como criar novos espaços institucionais voltados a uma política de náo-repetiçáo reincinde como uma tarefa urgente dentro de um contexto de revisionismos e tentativa de disputa de narrativa e legitimaçáo de uma memória positiva dos tempos autoritários.
A força permanente da política da memória continua a ser essencial para garantir os direitos humanos no futuro. Por mais que sua presença seja essencial para estabelecer regimes de direitos humanos onde eles ainda não existem, não podemos esquecer que a memória também pode alimentar violaçóes dos direitos humanos, do mesmo modo que os direitos humanos estáo expostos aos abusos políticos (HUYSSEN, 2014, p. 210) Entendendo que "a memória emerge de um grupo que ela une" (NORA, 1993, p. 9), fica explícita a tentativa de "salvar os cacos do passado", "abandonados pela humanidade carregada pelo "progresso" no seu caminhar cego" (SELIGMANN-SILVA, 2003, p.77), ligando e construindo memória sobre as experiências realizadas em diferentes cidades da América Latina (Buenos Aires, especificamente no saguão do seu Colegio Nacional, onde fica a fotografia de Marcelo Brodsky; São Paulo, com o Memorial da Resistência; e Rio de Janeiro, com a Campanha Ocupa DOPS), sendo algumas dessas ligaçôes: primeiro, o caráter dito "subversivo" (que era uma palavra muito utilizada para designar quem era contra o Regime Militar), entendido aqui como transformador, dessas memórias; segundo, o potencial investigativo das diversas camadas de memória - entendida como "por natureza, múltipla e desacelerada, coletiva, plural e individualizada.”, enraizada "no concreto, no espaço, no gesto, na imagem, no objeto." (NORA, 1993, p. 9); terceiro, a criaçáo de lugares de memória (mesmo que provisórios, no caso dos eventos da Campanha Ocupa DOPS) em que "as fronteiras entre passado e presente tornam-se fluidas" possibilitando a aproximação com o tema (HUYSSEN, 2014, p. 172) "como um modo de reparar o dano" (GONDAR e DODEBEI, 2005, p.9); seguindo de um quarto elo, que é o destaque da arte e da cultura como abordagem do tema da memória. 
Sobre essa última ligação, é importante destacar que "A memória da ditadura foi crucial para sucesso da transição para a democracia na Argentina (...) [que] tem os mais intensos debates sobre a memória entre os países latino-americanos que foram atormentados pelas campanhas militares" (HUYSSEN, 2014, p. 161). Além do reconhecimento por julgar e condenar torturadores, "o foco jurídico na ditadura foi complementado por um intenso foco cultural, que levou a projetos muito discutidos de memoriais em Buenos Aires, La Plata, Tucumán e outras regióes do país" (idem, p. 164). Diferente do Brasil, na vizinha latino-americana, parte do trabalho de justiça de transição se deu e se dá através de memoriais e instituições voltadas para a temática das violaçóes de direitos humanos, relacionando passado e presente assim como fez Marcelo Brodsky em sua série fotográfica, onde "um elo é construído entre passado e presente ao se colocar o antigo registro de escola como elemento principal das novas imagens" (SANTOS, 2018, p.6).

Entendendo que toda sociedade brasileira foi e é afetada pelas violaçóes de direitos humanos do Estado no passado e no presente (uns mais, outros menos), e que, apesar disso, o fato desses grupos serem marcados por uma perseguição ou opressão não garante que tenham uma memória grupal coletiva sobre essa realidade (HUYSSEN, 2014, p. 205), fica evidente a necessidade de construção de uma memória e uma cultura dos direitos humanos no Brasil que articule passado, presente e futuro.

articular historicamente o passado não significa reconhecê-lo 'tal qual ele foi'. Significa apoderarmo-nos de uma recordação (Erinnerung) quando ela surge como um clarão num momento de perigo (BENJAMIN, 2013, p.11).
Resguardada a necessidade de criação e manutenção desses espaços de memória voltados aos direitos humanos e à arte, os trabalhadores do campo da educaçâo e da cultura comprometidos com o tema têm um papel importantíssimo, que é o de, além de se fazer conhecer e relacionar trabalhos artísticos latino-americanos com seus contextos políticos e memórias individuais e coletivas; problematizar os signos, símbolos, imagens e mensagens deixadas intencionalmente por figuras do Estado autoritário; assim como investigar e trabalhar sensivelmente sob os rastros e testemunhos dessas memórias de uma maneira crítica, voltando os vestígios de violência contra ela própria, ameaçando-a (GAGNEBIN, 2006, p.12) e consolidando uma coletividade mais solidária e libertadora.

\section{Notas de fim:}

1. Marcelo Brodsky(1954) é artista e ativista pelos direitos humanos e vive em Buenos Aires, onde nasceu. Durante o exílio, além de estudar Fotografia no Centro Internacional de la Fotografía, estudou economia na Universidad de Barcelona. Com trabalhos que exploram a relação entre imagem e texto, sua obra passa por fotografia, vídeos, performance e monumento, e atualmente faz parte de grandes acervos como a Tate Collection de Londres e o Metropolitan Museum of Art, em Nova York, além do Museu de Arte Moderna do Rio de Janeiro e da Pinacoteca do Estado de São Paulo. É membro da Asociación Buena Memoria, uma organização de direitos humanos, e do conselho de gestão do Parque de la Memoria do Rio de La Plata, em homenagem às vítimas do terrorismo de estado, além de ser um dos fundadores da Visual Action, uma organização que, a partir de conhecimentos da cultura e educação visual, promove campanhas de direitos humanos.

2. Após um conturbado período de golpe e deposição da Dilma Roussef, em 2016, condenação em uma prisão política sem provas do candidato a presidência com maior vantagem nas pesquisas, o ex-presidente Lula, em 
2018, justamente pelo juiz, atual ministro da Justiça, e já indicado pelo presidente a futuro ministro do Supremo Tribunal Federal, Sérgio Moro, conforme reportagens a seguir do El Pais, Rede Brasil Atual e Folha de São Paulo: $<$ https://brasil.elpais.com/brasil/2016/08/31/opinion/1472650538_750062.html>

<https://www.redebrasilatual.com.br/politica/2019/05/ associacao-americana-de-juristas-reconhece-lula-como-preso-politico>

<https://www1.folha.uol.com.br/poder/2019/05/bolsonaro-diz-que-vai-indicar-sergio-moro-para-vaga-no-stf. shtml>

3.Sob a denominação de "auto de resistência", aumenta $\mathrm{o}$ assassinato da população periférica durante confrontos em 387,5\% no estado do Rio de Janeiro de 2014 a 2017, conforme reportagens: https://oglobo.globo.com/ rio/autos-de-resistencia-nas-upps-cresceram-3875-no-estado-do-rio-22993568 e <https://pt.globalvoices. org/2015/02/10/entenda-o-que-e-o-auto-de-resistencia-no-brasil-e-o-que-esta-sendo-feito-para-acabar-com-eles/>

4. Conforme elucida Lucas Pedretti em seu artigo Memórias Morro Acima: A Ditadura nas Favelas Cariocas e as Comissóes da Verdade: <http://seminariosmemoriasocial. pro.br/wp-content/uploads/2016/03/A007-LUCAS-PEDRETTI-normalizado.pdf>

5. Eric Nepomucento, em seu livro "A Memória de Todos Nós”, trás uma fala de Leonardo Boff em Seminário da Faculdade Latino-Americana de Ciências Sociais, em 2012 - de onde foi tirada a frase.

6. Número alcançado durante a ação, mas recentemente chegou-se ao número 108, como é possível acessar através da publicação da reitoria do Colégio de novembro de 2011: <https://www.cnba.uba.ar/category/etiquetas/ desaparecidos>

7. Essas informaçóes foram acessadas através de uma consulta ao Arquivo Histórico e Institucional do Museu da República (AHI/MR), no Rio de Janeiro, onde também foi possível notar que essa instituição foi a primeira a receber a exposição com este nome, Buenas Memorias (a ação realizada em 1996 no CNBA era uma exposiçáo coletiva entitulada "Desaparecidos"), sendo que contava com apenas 49 fotografias e 2 vídeos - o que indica que a série ainda estava em desenvolvimento nessa época. No dia de sua abertura, 22 de outubro de 1996, também foi lançado o livro "Buena Memoria: um ensaio fotográfico", e a exposição ficou aberta durante um mês. Também foi constatado que o Brasil foi o segundo lugar fora da Argentina (o primeiro foi o México, com a exposição Itinerarios, em 1996) a abrigar uma exposição individual do artista.

8. Como é possível acessar na reportagem a seguir: $<$ https://politica.estadao.com.br/noticias/geral,grupo-debate-destino-do-predio-onde-funcionou-dops-no-rj,1546397>

9.O que não quer dizer que, antes disso, não houvesse esse pedido e disputa pelo prédio. O Grupo Tortura Nunca Mais, por exemplo, já reivindicava essa transformação. $\mathrm{O}$ recorte desse artigo é a Campanha Ocupa DOPS, propriamente dita, que surgiu no contexto da criação das Comissóes da Verdade, a partir do Coletivo RJ Memória, Verdade e Justiça. Na reportagem do Extra a seguir, de 2010, é possível verificar isso: <https://extra.globo.com/ noticias/rio/dops-cem-anos-de-um-simbolo-da-historia-politica-52156.html>

\section{Referências Bibliográficas:}

ARAUJO, Marcelo Mattos; BRUNO, Maria Cristina Oliveira. Memorial da Resistência de São Paulo. São Paulo: Pinacoteca do Estado, 2009.

BARBA, Mariana Della e WENTZEL, Marina. Discurso de Bolsonaro deixa ativistas 'estarrecidos' e leva $O A B$ a pedir sua cassação. BBC Brasil. São Paulo e Basileia, 20 de abril de 2016. Disponível em: <https://www.bbc.com/ portuguese/noticias/2016/04/160415_bolsonaro_ongs_ oab_mdb> Acesso em 19 maio 2019.

BENJAMIN, Walter. Benjamin e a obra de arte: técnica, imagem, percepção. Rio de Janeiro: Contraponto, 2012.

BENJAMIN, Walter. $O$ anjo da história. Tradução João 
Barrento. 2a edição. Belo Horizonte: Autêntica Editora, 2013.

BENJAMIN, Walter. Sobre o Conceito de História. Obras Escolhidas, vol. 1. São Paulo: Brasiliense, 2012.

BRASIL é condenado por não investigar assassinato e tortura de Vladimir Herzog. El País. San José, 5 de julho de 2018. Disponível em: <https://brasil.elpais.com/ brasil/2018/07/04/politica/153073428_207748.html> Acesso em 19 maio 2019.

BRODSKY, Marcelo. Marcelo Brodsky. Site oficial do Artista. Disponível em: <https://marcelobrodsky.com> Acesso em 19 maio 2019.

CNBA. Colegio Nacional de Buenos Aires. Site oficial da escola. Disponível em: <https://www.cnba.uba.ar/category/ etiquetas/desaparecidos> Acesso em 19 maio 2019.

DEISTER, Jaqueline. "Ditadura tornou a tortura regular", diz sobrevivente do golpe de 64. Brasil de Fato, Rio de Janeiro, 28 de março de 2019. Disponível em: <https:// www.brasildefato.com.br/2019/03/28/ditadura-tornou-a-tortura-regular-diz-sobrevivente-do-golpe-de-64/> Acesso em 19 maio 2019.

FILHOS E NETOS. Filhos e Netos por Memória, Verdade e Justiça RJ. Página do movimento social ligado ao tema da memória, verdade e justiça e da violência estatal de ontem e hoje. Disponível em: <https://filhosenetos.wordpress.com/2017/01/> Acesso em 19 maio 2019.

FREIRE, Paulo. Educação como Prática da Liberdade. Rio de Janeiro: Paz e Terra, 1981.

FREIRE, Paulo. Pedagogia da Autonomia: saberes necessários à prática educativa. São Paulo: Paz e Terra, 1996.

FREIRE, Paulo. Pedagogia da Indignaçâo: cartas pedagógicas e outros escritos. São Paulo: Editora UNESP, 2000.

GAGNEBIN, Jeanne-Marie. Lembrar escrever esquecer. São Paulo: Ed.34, 2006

GANGRA, Alana. Secretaria do Rio apresenta projeto para transformar prédio do Dops em museu. Agência Brasil, Rio de janeiro, 12 de dezembro de 2016. Disponível em: $<$ http://agenciabrasil.ebc.com.br/direitos-humanos/noticia/2016-12/secretaria-do-rio-apresenta-projeto-para-transformar> Acesso em 19 maio 2019.
GÓMES, José Maria. A Justiça Transicional e o Imprevisivel Jogo entre a Politica, a Memória e a Justiça, 2014. In Revista Comunicaçôes do ISER no 68 - 50 Anos da Ditadura no Brasil: Memórias e Reflexões, 2014.

GOMES, Luiz Flávio. A Lei da Anistia viola convençôes de Direitos Humanos. Revista Consultor Jurídico, São Paulo, 10 de Março de 2011. Disponível em: <https://www. conjur.com.br/2011-mar-10/coluna-lfg-lei-anistia-viola-convencoes-direitos-humanos> Acesso em 19 maio 2019.

GONDAR, Jô; DODEBEI, Vera. O que é memória social. Rio de Janeiro: UNIRIO, 2005.

GUERRA, Rayanderson. Justiça mantém condenação de Bolsonaro a pagar $R \$ 150$ mil por declaraçôes homofóbicas e racistas. Extra, Rio de Janeiro, 9 de maio de 2019. Disponível em: <https://extra.globo.com/noticias/brasil/justica-mantem-condenacao-de-bolsonaro-pagar-150-mil-por-declaracoes-homofobicas-racistas-rv1-1-23653914. html> Acesso em 19 maio 2019.

GRUPO debate destino do prédio onde funcionou Dops no $R J$. Estadáo, São Paulo, 14 de agosto de 2014. Disponível em: <https://politica.estadao.com.br/noticias/geral,grupo-debate-destino-do-predio-onde-funcionou-dops-no-rj,1546397> Acesso em 19 maio 2019.

HUYSSEN, Andreas. Culturas do passado-presente: modernismos, artes visuais, politicas da memória. Rio de Janeiro: Contraponto; Museu de Arte do Rio, 2014.

INEPAC. Instituto Estadual do Patrimônio Artístico e Cultural. Publicação do Processo de tombamento do prédio. Disponível em: <http://www.inepac.rj.gov.br/index.php/ bens_tombados/detalhar/270> Acesso em 19 maio 2019.

LAGO, Rudolfo. Exclusivo: a farra das indenizaçôes. Istoé, Rio de Janeiro, 7 de fevereiro de 2019. Disponível em: $<$ https://istoe.com.br/a-farra-das-indenizacoes/> Acesso em 19 maio 2019.

MARINATTO, Luã. Autos de resistência nas UPPs cresceram 387,5\% no Estado do Rio. O Globo, Rio de Janeiro, 20 de agosto de 2018. Disponivel em: <https://oglobo. globo.com/rio/autos-de-resistencia-nas-upps-cresceram-3875-no-estado-do-rio-22993568> Acesso em 15 julho 2019 
Museu da República, BRRJMRAHI Evento/Exposição curta.

NAIDU, Eresh nee. Da Memória à Ação. Um Kit de Ferramentas para Memorialização em Sociedades Pós-Conflito. Tradução: Arial Caniza. International Coalition of Sites of Conscience. Brasília : Comissão de Anistia / Ministério da Justiça (Brasil), 2010.

NEPOMUCENO, Eric. A Memória de Todos Nós, Rio de Janeiro: Record, 2015.

NINIO, Marcelo. Bolsonaro lembra discurso em homenagem ao Ustra ao encontrar brasileiros em Israel. O Globo, Jerusalém, 2 de abril de 2019. Disponível em: <https:// oglobo.globo.com/mundo/bolsonaro-lembra-discurso-em-homenagem-ustra-ao-encontrar-brasileiros-em-israel-23568356> Acesso em 19 maio 2019.

NORA, Pierre. Entre memória e história: a problemática dos lugares. Projeto História. São Paulo: PUC-SP. No 10. 1993.

NÚCLEO MEMÓRIA. Núcleo de Preservação de Memória Politica. Sessão do site que fala sobre REBRALUME. Disponível em: <https://www.nucleomemoria.com.br/ rebralume> Acesso em 19 maio 2019.

PEDRETTI, Lucas. Memórias morro acima: a Ditadura nas favelas cariocas e as Comissöes da Verdade. In: Seminário Internacional em Memória Social, 2016, Rio de Janeiro. Anais do II Seminário Internacional em Memória Social, 2016.

PINACOTECA. Pinacoteca do Estado de Sáo Paulo. Texto da exposição Buena Memoria. Disponível em: <https://pinacoteca.org.br/programacao/buena-memoria/> Acesso em 19 maio 2019.

POST, Fabiano. Entenda o que é auto de resistência no Brasil e o que está sendo feito para acabar com eles. Global Voices. Rio de Janeiro, 10 de fevereiro de 2015. Disponível em: <https://pt.globalvoices.org/2015/02/10/entenda-o-que-e-o-auto-de-resistencia-no-brasil-e-o-que-esta-sendo-feito-para-acabar-com-eles/> Acesso em 14 julho 2019.

REGISTRADO pedido de CPI para investigar reparaçóes a anistiados políticos. Senado Notícias. Brasília, 13 de fevereiro de 2019. Disponível em: <https://www12.senado. leg.br/noticias/materias/2019/02/13/registrado-pedido-de-cpi-para-investigar-reparacoes-a-anistiados-politicos> Acesso em 19 maio 2019.

RIO: antigo prédio do Dops tem estrutura em risco e documentos abandonados. Portal R7, Rio de Janeiro, 13 de abril de 2015. Disponível em: <https://noticias.r7.com/rio-de-janeiro/fotos/rio-antigo-predio-do-dops-tem-estrutura-em-risco-e-documentos-abandonados-13042015\#!/ foto/2> Acesso em 19 maio 2019.

SANTOS, Ana Carolina Lima. Entrevendo olhares espectrais : as fotografias de vitimas das ditaduras em obras de arte contemporâneas. ARS, São Paulo, v. 16, p. 233-259, 2018. Disponível em: <https://www.revistas.usp.br/ars/article/ view/137293>. Acesso em 19 maio 2019.

SELIGMANN-SILVA, Márcio. Reflexóes sobre a memória, a história e o esquecimento. In História, Memória, Literatura. O testemunho na era das catástrofes (pp. 59-89). Campinas: Editora da UNICAMP, 2003.

SELIGMANN-SILVA, Márcio. Narrar o trauma: a questão dos testemunhos de catástrofes históricas. Psicol. clin. [online]. vol.20, n.1, pp.65-82, 2008.

SILANO, Ana Karoline e FONSECA, Bruno. Ministério dos Direitos Humanos nega 33 pedidos de anistia para cada solicitação aprovada. Pública. São Paulo, 19 de abril de 2019. Disponível em: <https://apublica.org/2019/04/ ministerio-dos-direitos-humanos-nega-33-pedidos-de-anistia-para-cada-solicitacao-aprovada/> Acesso em 19 maio 2019.

SOARES, Inês Virgínia Prado; QUINALHA, Renan Honório. Os escrachos e a luta por verdade e justiça "desde baixo", 2013. In Revista Comunicaçóes do ISER no 68 - 50 Anos da Ditadura no Brasil: Memórias e Reflexóes, 2014.

SOUZA, Taiguara Libano Soares e. Tortura Ontem e Hoje: breve balanço da justiça de transiçāo no Brasil, 2013. In Revista Comunicaçóes do ISER no 68 - 50 Anos da Ditadura no Brasil: Memórias e Reflexões, 2014.

VILELA, Pedro Rafael. Bolsonaro autoriza celebração do 31 de março de 1964. Agência Brasil, Brasília, 25 de março de 2019. Disponível em: <http://agenciabrasil.ebc.com.br/ politica/noticia/2019-03/bolsonaro-autoriza-celebracao-do-31-de-marco-de1964> Acesso em 19 maio 2019. 